was made. Chase Farm Hospital is a district general hospital that has a clinical decision unit, a short stay ward along with a speciality based ward triage for GIM patients. Data were obtained from medical notes and discharge summaries.

Results 62 patients ( 29 male, 33 female), median age 72.5 years were admitted over the study period. 38 patients $(61.3 \%)$ had no other acute non-GI diagnoses requiring prompt treatment. 24 patients $(38.7 \%)$ had at least one other non-GI diagnosis (range 1-2): 16 patients $(25.8 \%)$ had one and eight patients $(12.9 \%)$ had two active non-GI diagnosis. The most common non-GI diagnosis was cardiovascular in origin $(9,37.5 \%)$. Other non-GI diagnoses were respiratory $(6,25 \%)$, renal $(6,25 \%)$, endocrine $(6,25 \%)$, or other $(4$, $16.6 \%)$. Of these patients, $5(20.8 \%)$ required referral to a specialist team for further investigation and/or treatment of their condition. Conclusion A significant number of patients ( $39 \%$ ) admitted as an acute medical emergency with a primary GI diagnosis have other active non-GI medical diagnoses. The majority of these were managed by gastroenterology and only in one in five patients was a specilaist opinion sort for further management. By training and maintaining skills in GIM, gastroenterologists are more able to independently manage acute medical patients admitted with a primary GI diagnosis and avoid inter-specialty referral in up to $25 \%$ of patients. From this study we support the dual accreditation sought by gastroenterology trainees in GIM.

Competing interests None declared.

\section{PTU-264 PROVIDING A COLONIC STENTING SERVICE FOR MALIGNANT BOWEL OBSTRUCTION: A DISTRICT GENERAL HOSPITAL EXPERIENCE}

doi:10.1136/gutjnl-2012-302514c.264

${ }^{1} Y$ H Siaw, ${ }^{*} \mathrm{~N}$ Joshi, ${ }^{1}$ E Selvaraj, ${ }^{1} \mathrm{~L}$ Steward, ${ }^{1} \mathrm{R}$ Greaves, ${ }^{1} \mathrm{~A}$ Watson, ${ }^{1} \mathrm{~S}$ Hoque, ${ }^{1} \mathrm{E}$ Seward. 'Department of Gastroenterology, Whipps Cross University Hospital, London, UK; ${ }^{2}$ Department of Gastroenterology, Royal London Hospital, London, UK

Introduction There is growing evidence for the efficacy and safety for the insertion of self expanding metal stents (SEMS) in the treatment of acute malignant colonic obstruction. ${ }^{1}$ This allows either palliation or a bridge to surgery in an otherwise acutely unwell patient. Colonic stenting literature quotes technical success rates in excess of $85 \%$. ${ }^{1-4}$ Our unit has been inserting colonic SEMS since 2006. Prior to this we had extensive experience in therapeutic endoscopy but not in colonic stenting. We have observed a learning curve with colonic stenting that is encouraging for endoscopists who are considering implementing the technique.

Methods All SEMS insertions from July 2006 to December 2011 were analysed retrospectively by examining a combination of endoscopy reports, the CRC database and patient notes. A successful SEMS deployment was defined as: satisfactory radiological and endoscopic evidence of colonic decompression at time of deployment and clinical improvement. All SEMS insertion successes and failures were collated and the data compared in consecutive groups of ten procedures.

Results 70 SEMS insertions were attempted in 62 patients. Each procedure is carried out endoscopically with radiological guidance by a gastroenterologist. Ten (14.3\%) of the stents were proximal to the splenic flexure. The overall success rate for SEMS deployment was $88.6 \%(n=62)$. Abstract PTU-264 figure 1 shows the success rates improvement with the number of procedures carried out. 7 of the 8 failures occurred in the first 20 procedures carried out in our unit. Reasons for unsuccessful procedures are failure to traverse stricture with guidewire $(n=5)$, stent slippage $(n=2)$ and poor bowel prep \& excessive looping $(n=1)$. Overall complications rates were low. There were two perforations $(2.9 \%)$, one of which underwent emergency surgery while the other was managed conservatively.
Restenosis occurred in two patients $(2.9 \%)$ and tumour overgrowth occurred in 1 (1.4\%).

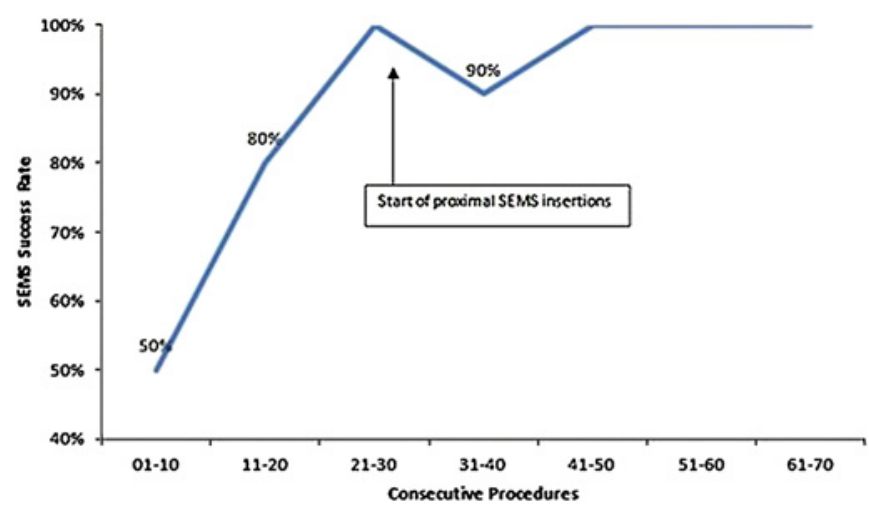

Abstract PTU-264 Figure 1

Conclusion SEMS technology is now readily available and is a safe and effective means of treating malignant colonic obstruction. As with all new techniques there is a learning curve associated with its implementation. We have shown that the learning curve is surmountable and that potentially any unit could offer a colonic SEMS service.

Competing interests None declared.

\section{REFERENCES}

1. Vemulapalli R, Lara LF, Sreenarasimhaiah J, et al. Dig Dis Sci 2010;55:1732-7

2. Manes G, de Bellis M, Fuccio L, et al. Arch Surg 2011;146:1157-62.

3. Foo C, Poon JT, Law WL. Colorectal Dis 2010;13:549-54.

4. Olubaniyi BO, McFaul CD, Yip VSK, et al. Ann R Coll Surg Eng 2008;91:55-8.

\section{Trainees}

\section{PTU-265 IMPROVING EDUCATION QUALITY AND ATTENDANCE OF A REGIONALLY DELIVERED GASTROENTEROLOGY EDUCATION PROGRAMME}

doi:10.1136/gutjnl-2012-302514c.265

${ }^{1} \mathrm{~A} J$ Brooks, ${ }^{*}{ }^{1} \mathrm{M}$ Kurien, ${ }^{2} \mathrm{G}$ James, ${ }^{3} \mathrm{P}$ Basumani, ${ }^{1} \mathrm{D} S$ Sanders, ${ }^{4} \mathrm{~K}$ Kapur. ${ }^{1}$ Department of Gastroenterology, Sheffield Teaching Hospitals NHS Foundation Trust, Sheffield, UK; ${ }^{2}$ Department of Gastroenterology, Doncaster Royal Infirmary, Doncaster, UK; ${ }^{3}$ Department of Gastroenterology, Rotherham General Hospital, Rotherham, UK; ${ }^{4}$ Department of Gastroenterology, Barnsely Hospital, Barnsley, UK

Introduction The 2010 competency based speciality-training curriculum for gastroenterology requires trainee's to obtain multiple learning objectives. To ensure these are met training programme directors and postgraduate deaneries need to implement changes in delivery of local education programmes. The aim of this study was to determine factors in the delivery of a locally organised and delivered gastroenterology teaching programme that have the greatest impact on improving educational quality and attendance. Methods All consultants and gastroenterology trainees within a deanery received a questionnaire evaluating the 2009-2010 competency based training programme. Responses were compared with data obtained evaluating a previous training programme between 2003 and 2009 designed around the 2003 gastroenterology curriculum involving 6-weekly, half day events at local hospitals organised by individual consultants. Significant interventions made to the new programme included a predetermined programme guide, whole day events, single venue, keynote speakers, continual professional development points, a local training website and increased trainee involvement in programme development. 
Results The majority (15/19) of respondents regarding the competency based training programme attended $\geq 50 \%$ or more of events, compared to only $7 / 24$ in the 2003 curriculum based programme $(p=0.001)$. Of the 11 trainee's in the region, a response rate of $73 \%$ was obtained with a significantly greater proportion (89\%) stating that the competency based training programme met their training needs, compared to $42 \%$ surveyed on the 2003 curriculum based programme $(p=0.001)$. Reasons for lack of attendance included insufficient time to cancel clinical commitments and poor educational value of the 2003 curriculum based programme. Consultant attendance at training meetings increased significantly following redesign of the programme, with $64 \%$ attending $>50 \%$ of meetings compared $12 \%$ prior to instituting a competency based training programme ( $\mathrm{p}=0.004)$. The three most important factors to increase attendance were full day meetings, a consistent venue and keynote speakers from outside of the region.

Conclusion This longitudinal study is the first study to evaluate attendance and educational value of a competency based regional gastroenterology teaching programme. Despite increasing demand to provide service provision and restrictions on study leave allowance, implementation of simple measures as identified in this study may increase consultant attendance and educational quality of regionally organised teaching programmes.

Competing interests None declared.

\section{PTU-266 TRAINEE SATISFACTION WITH JAG E-CERTIFICATION}

doi:10.1136/gutjnl-2012-302514c.266

${ }^{1} \mathrm{~S}$ Dharmasiri, ${ }^{*} \mathrm{C}$ Wells, ${ }^{1} \mathrm{~L}$ Flexer, ${ }^{3} \mathrm{~S}$ Thomas-Gibson, ${ }^{1} \mathrm{P}$ Dunckley. ${ }^{*}{ }^{1}$ Department of Gastroenterology, Gloucester Royal Hospital, Gloucester, UK; ${ }^{2}$ Department of Gastroenterology, University Hospital of North Tees, Stockton on Tees, UK; ${ }^{3}$ Department of Gastroenterology, St Mark's Hospital, London, UK

Introduction In March 2011 JAG launched e-certification allowing trainees to apply for JAG certification through their JETS e-portfolio. Prior to this, trainees were required to submit paper portfolios for application of JAG certification. We report results of a quality assurance survey, which all trainees applying through the JETS eportfolio were invited to complete.

Methods All trainees applying through the JETS e-portfolio were invited to complete an online survey, created to assess trainee experience of e-certification. Trainees were asked if they strongly agreed (SA), agreed (A), were neutral $(\mathrm{N})$, disagreed $(\mathrm{D})$ or strongly disagreed (SD) with statements describing their experience of the process.

Results A total of 109 applications for JAG certification have been made through the JETS e-portfolio since its launch. Some trainees have submitted more than one application for certification in different endoscopic modalities. A total of 33 trainees $(30 \%$ of applications) completed the survey, 7 (21\%) of which had previously applied for JAG certification by the paper or hybrid (paper and eportfolio) methods. When questioned about the general process $69.2 \%$ agreed and $23.1 \%$ strongly agreed that it was better that the previous JAG certification process it replaced. The majority felt that the process was quicker $(\mathrm{SA}=42.9 \%, \mathrm{~A}=42.9 \%)$ and less time consuming ( $\mathrm{SA}=28.6 \%, \mathrm{~A}=57.1 \%$ ). Opinion was divided on cost; $48.5 \%$ agreed that the cost was reasonable and $15.2 \%$ were neutral but $30.3 \%$ disagreed and $6.1 \%$ strongly disagreed. The majority felt that a breakdown of costs would be helpful ( $\mathrm{SA}=18.2 \%, \mathrm{~A}=51.5 \%$, $\mathrm{N}=21.2 \%, \mathrm{D}=9.1 \%$ ). Trainees agreed that the process tested endoscopic competence across all the modalities: gastroscopy $(\mathrm{SA}=37.9 \%, \mathrm{~A}=62.1 \%)$, flexible sigmoidoscopy $(\mathrm{SA}=60 \%, \mathrm{~A}=40 \%)$ and colonoscopy $(\mathrm{SA}=44.4 \%, \mathrm{~A}=55.6 \%)$. There was agreement that the summative assessments were straightforward to submit $(\mathrm{SA}=48.4 \%, \quad \mathrm{~A}=51.6 \%)$ and intuitive $(\mathrm{SA}=32.3 \%, \mathrm{~A}=58.1 \%$,
$\mathrm{N}=9.7 \%$ ). Similarly trainees felt that the process of submitting the application by the JETS e-portfolio was straightforward ( $\mathrm{SA}=42.4 \%$, $\mathrm{A}=54.5 \%, \mathrm{~N}=3 \%$ ), quick ( $\mathrm{SA}=39.4 \%, \mathrm{~A}=54.5 \%, \mathrm{~N}=3 \%, \mathrm{D}=3 \%$ ) and that they were kept informed of their application progress ( $\mathrm{SA}=45.5 \%, \mathrm{~A}=45.5 \%, \mathrm{~N}=9.1 \%$ ).

Conclusion This survey of trainee experience with the JETS e-portfolio application for JAG certification shows that trainees prefer the process compared to the old paper system. It is quicker and trainees agreed the process tested endoscopy competence in gastroscopy, colonoscopy and flexible sigmoidoscopy. The opinion of trainees regarding the cost of the process was spit and trainees would find a breakdown of the cost helpful. The findings of this survey show that the new e-portfolio certification functions well and meets the needs of trainees.

Competing interests None declared.

\section{PTU-267 TRAINING IN GASTROENTEROLOGY IN SEVERN: IMPLEMENTATION OF CHANGE IMPROVES TRAINING}

doi:10.1136/gutjnl-2012-302514c.267

U Chelvaratnam, ${ }^{*}$ E Arthurs, T Mehta, S Pugh, M Lockett. Department of Gastroenterology, Severn Deanery, Bristol, UK

Introduction Feedback on training posts is collected by a variety of different bodies. The Quality Panel was developed to review the quality of gastroenterology training in the region. Feedback on training posts was found to be of variable quality, incomplete, and difficult to analyse. The aim was to create a specific, reproducible method of assessing gastroenterology and general internal medicine (GIM) training, to provide feedback on individual posts and facilitate improvements in training. In 2010 we conducted a survey of training within the region which identified specific areas for improvement which were fed back to individual trusts. This survey was repeated in 2011 to assess for changes.

Methods The 2010 survey comprised of 55 questions within seven domains of gastroenterology and GIM training. Questions were determined based on previous surveys and areas of importance according to consultant and trainee opinion. It was emailed to all registrars in the Severn deanery. Data were collected for the last 3 years of training (2007-2010); preserving anonymity and eliminating bias. Answers correlated to numerical scores, with high scores correlating with high quality. Mean scores were calculated per domain, per trust; a total score was then calculated. The data were presented to the Quality Panel and training committee. Individualised feedback was given to each trust. The survey was repeated in 2011 (with 18 additional questions) to monitor improvements and was analysed with data from 2008 to 2010.

Results The 2010 survey included 37 anonymised responses from 21 trainees at nine hospitals within the Severn region. Responses by trust varied from 3 to 9. Mean overall numerical score was 26.1 (range 24.4-28.6). All trusts scored lowest in providing GIM training with a mean score of 3.1 (range 2.7-3.6); educational support scored highest with a mean score of 4.4 (range $3.4-4.8$ ). The 2011 survey included 46 anonymised responses from 21 trainees at nine hospitals. Responses by trust varied from 3 to 8 . Mean overall numerical score was 26.8 (range 24.7-28.7) and 34.2 (range 31-36.8) with the additional questions. All trusts either improved or retained the same score. All trusts scored lowest in providing GIM training with a mean score of 3.3 (range 2.9-3.8); educational support scored highest with a mean score of 4.5 (range 4-4.8).

Conclusion Creation of a new survey achieved a good response rate and generated speciality specific outcomes and relevant data. This method of assessing training facilitates informed feedback to trusts Repetition of the survey has shown that feedback-led implementation of change has improved training in Severn. By collecting 